\title{
Calcium intake and bone mineral density: systematic review and meta-analysis
}

\author{
Vicky Tai,, William Leung,, ${ }^{2}$ Andrew Grey, ${ }^{1}$ lan R Reid, ${ }^{1}$ Mark J Bolland ${ }^{1}$
}

Department of Medicine, University of Auckland, Private Bag 92019, Auckland 1142, New Zealand

2Department of Public Health, University of Otago, PO Box

7343, Wellington 6242,

New Zealand

Correspondence to:

M Bolland

m.bolland@auckland.ac.nz

Additional material is published online only. To view please visit the journal online (http://dx.doi. org/10.1136/bmj.h4183)

Cite this as:BMJ 2015;351:h4183 doi: 10.1136/bmj.h4183

Accepted: 29 July 2015

\section{ABSTRACT}

OBJECTIVE

To determine whether increasing calcium intake from dietary sources affects bone mineral density (BMD) and, if so, whether the effects are similar to those of calcium supplements.

\section{DESIGN}

Random effects meta-analysis of randomised controlled trials.

\section{DATA SOURCES}

Ovid Medline, Embase, Pubmed, and references from relevant systematic reviews. Initial searches were undertaken in July 2013 and updated in September 2014.

\section{ELIGIBILITY CRITERIA FOR SELECTING STUDIES}

Randomised controlled trials of dietary sources of calcium or calcium supplements (with or without vitamin D) in participants aged over 50 with $B M D$ at the lumbar spine, total hip, femoral neck, total body, or forearm as an outcome.

\section{RESULTS}

We identified 59 eligible randomised controlled trials: 15 studied dietary sources of calcium $(n=1533)$ and 51 studied calcium supplements ( $\mathrm{n}=12257)$. Increasing calcium intake from dietary sources increased BMD by $0.6-1.0 \%$ at the total hip and total body at one year and by $0.7-1.8 \%$ at these sites and the lumbar spine and femoral neck at two years. There was no effect on BMD in the forearm. Calcium supplements increased BMD by $0.7-1.8 \%$ at all five skeletal sites at one, two, and over two and a half years, but the size of the increase in BMD at later time points was similar to the increase at one year. Increases in BMD were similar in trials of dietary sources of calcium and calcium supplements (except at the forearm), in trials of calcium monotherapy versus co-administered calcium and vitamin $D$, in trials with calcium doses of $\geq 1000$ versus $<1000 \mathrm{mg} /$ day and $\leq 500$ versus $>500 \mathrm{mg} /$ day, and in trials where the baseline dietary calcium intake was $<800$ versus $\geq 800 \mathrm{mg} /$ day.

\section{WHAT IS ALREADY KNOWN ON THIS TOPIC}

Older people are recommended to take at least 1000-1200 mg/day of calcium to treat and prevent osteoporosis

Many people take calcium supplements to meet these recommendations Recent concerns about the safety of such supplements have led experts to recommend increasing calcium intake through food rather than by taking supplements, but the effect of increasing dietary calcium intake on bone health is not known

\section{WHAT THIS STUDY ADDS}

Increasing calcium intake either by dietary sources or supplements has small non-progressive effects on bone density

These effects are unlikely to translate into clinically meaningful reductions in fractures

\section{CONCLUSIONS}

Increasing calcium intake from dietary sources or by taking calcium supplements produces small nonprogressive increases in BMD, which are unlikely to lead to a clinically significant reduction in risk of fracture.

\section{Introduction}

Maintaining a calcium intake of at least 1000-1200 mg/ day has long been recommended for older individuals to treat and prevent osteoporosis. ${ }^{12}$ Calcium supplements are commonly taken to achieve such intakes, which are considerably higher than the average intake of calcium in the diet in older people in Western countries, around 700-900 mg/day. Recently, concerns have emerged about the risk-benefit profile of calcium supplements. The small reductions in total fractures ${ }^{3}$ seem outweighed by the moderate risk of minor side effects such as constipation, coupled with the small risk of severe side effects such as cardiovascular events, ${ }^{4-6}$ kidney stones, ${ }^{7}$ and admission to hospital with acute gastrointestinal symptoms. ${ }^{8}$ Consequently, some experts have recommended that older people increase their calcium intake through their diet and take supplements only when that is not feasible. ${ }^{9}$ In a systematic review of calcium intake and fractures, we concluded that there was no evidence of an association between increased dietary calcium intake and lower risk of fracture. ${ }^{10}$ We identified only two small randomised controlled trials of dietary calcium intake that reported fracture as an outcome. Numerous cohort studies, however, assessed the relation between dietary calcium, milk or dairy intake, and risk of fracture, and most reported neutral associations. ${ }^{10}$

The putative mechanism by which calcium intake affects bone health is by increasing bone mineral density (BMD). BMD is a surrogate endpoint for fracture risk that allows biological effects to be explored in randomised controlled trials of modest size. We investigated whether the results of randomised controlled trials with BMD as an endpoint support the recommendations to increase dietary calcium intake to prevent osteoporosis. We undertook a systematic review and meta-analysis of randomised controlled trials of dietary sources of calcium or calcium supplements in older adults (aged $>50$ ) to determine whether increasing intake from dietary sources has effects on BMD and, if so, whether they are similar to the effects of calcium supplements on BMD.

\section{Methods}

\section{Literature search}

As part of a broader search for studies of calcium intake and health, we searched Ovid Medline and Embase in 
July 2013 and updated the search using Pubmed and Embase in September 2014 for randomised controlled trials of calcium, milk, or dairy intake, or calcium supplements with BMD as an endpoint. We also hand searched recent systematic reviews, meta-analyses, and any other articles included in our review for other relevant articles. Appendix 1 provided details of the searches.

\section{Patient involvement}

No patients were involved in setting the research question or the outcome measures, nor were they involved in the design and implementation of the study. There are no plans to involve patients in dissemination.

\section{Study selection}

Included studies were randomised controlled trials in participants aged $>50$ at baseline with BMD measured by dual energy x ray absorptiometry (DXA) or precursor technology such as photon absorptiometry. We included studies that reported bone mineral content (BMC) because BMD is obtained by dividing BMC by bone area and therefore the two are highly correlated. Studies in which most participants at baseline had a major systemic pathology other than osteoporosis, such as renal failure or malignancy, were excluded. We included studies of calcium supplements used in combination with other treatment provided that the other treatment was given to both arms (such as calcium plus vitamin $\mathrm{K}$ versus placebo plus vitamin $\mathrm{K}$ ), and studies of co-administered calcium and vitamin D supplements (CaD). Randomised controlled trials of hydroxyapatite as a dietary source of calcium were included because it is made from bone and contains other minerals, hormones, protein, and amino acids in addition to calcium. One author (WL or MB) screened titles and abstracts, and two authors (WL, MB, or VT) independently screened the full text of potentially relevant studies. The flow of articles is shown in figure $A$ in appendix 2.

\section{Data extraction and synthesis}

We extracted information from each study on participants' characteristics, study design, funding source and conflicts of interest, and BMD at the lumbar spine, femoral neck, total hip, forearm, and total body. BMD can be measured at several sites in the forearm, although the $33 \%(1 / 3)$ radius is most commonly used. For each study, we used the reported data for the forearm, regardless of site. If more than one site was reported, we used the data for the site closest to the $33 \%$ radius. A single author (VT) extracted data, which were checked by a second author (MB). Risk of bias was assessed as recommended in the Cochrane Handbook. ${ }^{11}$ Any discrepancies were resolved through discussion.

The primary endpoints were the percentage changes in BMD from baseline at the five BMD sites. We categorised the studies into three groups by duration: one year was duration $<18$ months; two years was duration $\geq 18$ months and $\leq 2.5$ years; and others were studies lasting more than two and a half years. For studies that presented absolute data rather than percentage change from baseline, we calculated the mean percentage change from the raw data and the standard deviation of the percentage change using the approach described in the Cochrane Handbook. ${ }^{11}$ When data were presented only in figures, we used digital callipers to extract data. In four studies that reported mean data but not measures of spread, ${ }^{12-15}$ we imputed the standard deviation for the percentage change in BMD for each site from the average site and duration specific standard deviations of all other studies included in our review. We prespecified subgroup analyses based on the following variables: dietary calcium intakev calcium supplements; risk of bias; calcium monotherapy $v \mathrm{CaD}$; baseline age (<65); sex; communityv institutionalised participants; baseline dietary calcium intake $<800 \mathrm{mg}$ /day; baseline 25 -hydroxyvitamin $\mathrm{D}<50 \mathrm{nmol} / \mathrm{L}$; calcium dose $(\leq 500 \mathrm{v}$ $>500 \mathrm{mg} /$ day and $<1000 \mathrm{v} \geq 1000 \mathrm{mg} /$ day); and vitamin D dose $<800$ IU/day.

\section{Statistics}

We pooled the data using random effects meta-analyses and assessed for heterogeneity between studies using the $\mathrm{I}^{2}$ statistic $\left(\mathrm{I}^{2}>50 \%\right.$ was considered significant heterogeneity). Funnel plots and Egger's regression model were used to assess for the likelihood of systematic bias. We included randomised controlled trials of calcium with or without vitamin D in the primary analyses. Randomised controlled trials in which supplemental vitamin D was provided to both treatment groups, so that the groups differed only in treatment by calcium, were included in calcium monotherapy subgroup analyses, while those comparing co-administered $\mathrm{CaD}$ with placebo or controls were included in the CaD subgroup analyses. We included all available data from trials with factorial designs or multiple arms. Thus, for factorial randomised controlled trials we included all study arms involving a comparison of calcium versus no calcium in the primary analyses and the calcium monotherapy subgroup analysis, but only arms comparing $\mathrm{CaD}$ with controls in the CaD subgroup analysis. For multi-arm randomised controlled trials, we pooled data from the separate treatment arms for the primary analyses, but each treatment arm was used only once. We undertook analyses of prespecified subgroups using a random effects model when there were 10 or more studies in the analysis and three or more studies in each subgroup and performed a test for interaction between subgroups. All tests were two tailed, and $\mathrm{P}<0.05$ was considered significant. All analyses were performed with Comprehensive Meta-Analysis (version 2, Biostat, Englewood, NJ).

\section{Results}

\section{Baseline characteristics}

We identified 59 randomised controlled trials of calcium intake that reported BMD as an outcome. ${ }^{712-70}$ Fifteen studied dietary sources of calcium $(n=810$ calcium, $n=723$ controls), ${ }^{16-30}$ and 51 studied calcium supplements $(n=6547$ calcium, $n=5710$ controls). ${ }^{72-151719-22262831-70}$ Table 1 shows study design and selected baseline characteristics for included studies of dietary calcium. Tables 2 and 3 show the study design 
Table 1 | Design of randomised controlled trials and selected baseline characteristics of eligible trials of dietary calcium

\begin{tabular}{|c|c|c|c|c|c|c|c|c|c|}
\hline Trial & Design & $\begin{array}{l}\text { Calcium } \\
\text { dose } \\
(\mathrm{mg} / \mathrm{d})\end{array}$ & $\begin{array}{l}\text { Vitamin D dose } \\
\text { (IU/d) }\end{array}$ & Duration & $\begin{array}{l}\text { Care } \\
\text { setting }\end{array}$ & $\begin{array}{l}\text { Total No of } \\
\text { participants* }\end{array}$ & $\begin{array}{l}\text { No in } \mathrm{Ca} / \\
\text { controls } \\
\text { groupt }\end{array}$ & \% women & $\begin{array}{l}\text { Mean } \\
\text { age } \\
\text { (years) }\end{array}$ \\
\hline Recker $1985^{16}$ & 2 arm: milk and control & NS & - & $2 y$ & Community & 30 & $16 / 14$ & 100 & 59 \\
\hline Polley $1987^{17}$ & 4 arm: dairy, Ca, dairy/salt restrict, control & $\geq 1250$ & - & $9 \mathrm{mo}$ & Community & 269 & $58 / 52$ & 100 & 57 \\
\hline Nelson $1991^{18}$ & $\begin{array}{l}2 \times 2 \text { factorial: ex/milk, ex/control, sed/milk, } \\
\text { sed/control }\end{array}$ & 831 & - & $1 \mathrm{y}$ & Community & 41 & $18 / 18$ & 100 & 60 \\
\hline Chevalley $1994^{19}$ & 3 arm: OMC/D, CaD, P/D & 800 & $300000 \mathrm{IM}$ stat & $18 \mathrm{mo}$ & Community & 93 & $31 / 31$ & 85 & 72 \\
\hline Prince $1995^{20}$ & 4 arm: milk, $\mathrm{Ca}, \mathrm{Ca} / \mathrm{ex}, \mathrm{P}$ & 1000 & - & $2 \mathrm{y}$ & Community & 168 & $42 / 42$ & 100 & 63 \\
\hline Storm $1998^{21}$ & 3 arm: milk, Ca, $P$ & NS & - & $2 y$ & Community & 40 & $20 / 20$ & 100 & 71 \\
\hline Castelo-Branco $1999^{22}$ & 3 arm: $\mathrm{OHC}, \mathrm{Ca}$, control & 3320 & - & $2 y$ & Community & 60 & $17 / 16$ & 100 & 55 \\
\hline Cleghorn $2001^{23}$ & 2 arm: milk, control & 700 & - & $1 \mathrm{y}$ & Community & 142 & $56 / 59$ & 100 & 52 \\
\hline Lau $2001^{24}$ & 2 arm: milk, control & 800 & - & $24 \mathrm{mo}$ & Community & 200 & $95 / 90$ & 100 & 57 \\
\hline Chee $2003^{25}$ & 2 arm: milk, control & 1200 & - & $24 \mathrm{mo}$ & Community & 200 & $91 / 82$ & 100 & 59 \\
\hline Albertazzi $2004^{26}$ & 3 arm: OHC, Ca, P & 500 & - & $6 \mathrm{mo}$ & Community & 153 & $52 / 50$ & 100 & 68 \\
\hline Daly $2006^{27}$ & 2 arm: milk, control & 1000 & 800 & $2 y$ & Community & 167 & $85 / 82$ & 0 & 62 \\
\hline Manios $2007^{28}$ & 3 arm: dairy, Ca, control & 1200 & 300 & $12 \mathrm{mo}$ & Community & 112 & $39 / 36$ & 100 & 61 \\
\hline Kukuljan $2009^{29}$ & $2 \times 2$ factorial: milk, milk/ex, ex, control & 1000 & 800 & $12 \mathrm{mo}$ & Community & 180 & $90 / 90$ & 0 & 61 \\
\hline Gui $2012^{30}$ & 3 arm: milk, soy milk, control & 250 & - & $18 \mathrm{mo}$ & Community & 141 & $100 / 41$ & 100 & 56 \\
\hline
\end{tabular}

$\mathrm{Ca}=$ calcium; restrict=restriction; ex=exercise; sed=sedentary; $\mathrm{OMC}=$ ossein-mineral complex; D=vitamin D; CaD=co-administered Ca and vitamin D; P=placebo; IM=intramuscular;

$\mathrm{OHC}=$ ossein-hydroxyapatite complex.

*Total number of randomised participants in all treatment arms.

tNumber of participants in relevant arms from trial in whom bone mineral density was reported.

Table 2 | Design of randomised controlled trials and selected baseline characteristics of eligible trials of calcium supplements

\begin{tabular}{|c|c|c|c|c|c|c|c|c|}
\hline Trial & Design & $\begin{array}{l}\text { Calcium dose } \\
(\mathrm{mg} / \mathrm{d})\end{array}$ & Duration & Care setting & $\begin{array}{l}\text { No of } \\
\text { participants* }\end{array}$ & $\begin{array}{l}\text { No in } \mathrm{Ca} / \text { controls } \\
\text { groupt }\end{array}$ & $\begin{array}{l}\% \\
\text { women }\end{array}$ & $\begin{array}{l}\text { Mean } \\
\text { age (y) }\end{array}$ \\
\hline Recker $1977^{31}$ & 3 arm: Ca, HRT, control & 1040 & $2 y$ & Community & 60 & $22 / 20$ & 100 & 57 \\
\hline Lamke $1978^{32}$ & 2 arm: Ca, $P$ & 1000 & $12 \mathrm{mo}$ & Community & 40 & 19/17 & 100 & 60 \\
\hline Hansson $1987^{12}$ & 4 arm: 30 mg NaF/Ca, 10 mg NaF/Ca, Ca, P & 1000 & $3 \mathrm{y}$ & NS & 50 & $25 / 25$ & 100 & 66 \\
\hline Polley $1987^{17}$ & 4 arm: Ca, dairy, dairy/salt restrict, control & 1000 & $9 \mathrm{mo}$ & Community & 269 & $40 / 52$ & 100 & 57 \\
\hline Riis $1987^{34}$ & 3 arm: Ca, HRT, P & 2000 & $2 y$ & Community & 43 & $14 / 11$ & 100 & 51 \\
\hline Smith $1989^{35}$ & 2 arm: Ca, P & 1500 & $4 y$ & Community & 169 & 70/77 & 100 & 51 \\
\hline Dawson-Hughes $1990^{36}$ & 3 arm: Ca, Ca, P & 500 & $2 y$ & Community & 361 & $158 / 93$ & 100 & 58 \\
\hline Fujita $1990^{37}$ & 2 arm: Ca, control & 900 & $2 y$ & Institution & 32 & $12 / 20$ & 100 & 80 \\
\hline Elders $1991^{39}$ & 3 arm: Ca, Ca, $P$ & 1000 or 2000 & $2 y$ & Community & 295 & $198 / 97$ & 100 & NS \\
\hline Prince $1991^{40}$ & 3 arm: $\mathrm{Ca} / \mathrm{ex}, \mathrm{ex}, \mathrm{HRT}$ & 1000 & $2 y$ & Community & 80 & $39 / 41$ & 100 & 57 \\
\hline Lau $1992^{42}$ & $2 \times 2$ factorial: $\mathrm{Ca}, \mathrm{Ca} / \mathrm{ex}, \mathrm{ex} / \mathrm{P}, \mathrm{P}$ & 800 & $10 \mathrm{mo}$ & Institution & 50 & $27 / 23$ & 100 & 76 \\
\hline Reid $1993^{43}$ & 2 arm: CavP & 1000 & $2 \mathrm{y}$ & Community & 135 & $61 / 61$ & 100 & 58 \\
\hline Strause $1994^{45}$ & $2 \times 2$ factorial: $\mathrm{Ca}, \mathrm{Ca} /$ minerals, minerals, $\mathrm{P}$ & 1000 & $2 y$ & Community & 113 & $27 / 32$ & 100 & 66 \\
\hline Prince $1995^{20}$ & 4 arm: $\mathrm{Ca}, \mathrm{Ca} / \mathrm{ex}$, milk, $\mathrm{P}$ & 1000 & $2 y$ & Community & 168 & $42 / 42$ & 100 & 63 \\
\hline Fujita $1996^{46}$ & 3 arm: Ca, Ca, P & 900 & $2 y$ & Institution & 58 & $38 / 20$ & 100 & 81 \\
\hline Perez-Jaraiz $1996^{47}$ & 4 arm: Ca, HRT, calcitonin, control & 1000 & $1 \mathrm{y}$ & Community & 52 & $26 / 26$ & 100 & 50 \\
\hline Recker 199648 & 2 arm: Ca, P & 1200 & $4.3 y$ & Community & 197 & $91 / 100$ & 100 & 74 \\
\hline Ricci $1998^{51}$ & 2 arm: Ca, $P$ & 1000 & $6 \mathrm{mo}$ & Community & 43 & $15 / 16$ & 100 & 58 \\
\hline Riggs $1998^{52}$ & 2 arm: Ca, P & 1600 & $4 \mathrm{y}$ & Community & 236 & $119 / 117$ & 100 & 66 \\
\hline Storm $1998^{21}$ & 3 arm: Ca, milk, $P$ & 1000 & $2 y$ & Community & 40 & $20 / 20$ & 100 & 72 \\
\hline Castelo-Branco $1999^{22}$ & 3 arm: Ca, OHC, control & 2500 & $2 y$ & Community & 60 & $19 / 16$ & 100 & 54 \\
\hline Ruml $1999^{53}$ & 2 arm: Ca, P & 800 & $2 y$ & Community & 63 & $25 / 31$ & 100 & 52 \\
\hline Fujita $2000^{54}$ & 4 arm: Ca, Ca, Ca, P & 900 & $4 \mathrm{mo}$ & NS & 38 & $32 / 6$ & 100 & 55 \\
\hline Peacock $2000^{13}$ & 3 arm: Ca, 25OHD, P & 750 & $4 \mathrm{y}$ & Community & 438 & $126 / 135$ & 72 & 74 \\
\hline Son $2001^{55}$ & 3 arm: Ca, alphacalcidiol, $\mathrm{P}$ & 1000 & $10 \mathrm{mo}$ & Community & 69 & $22 / 21$ & 100 & 72 \\
\hline Albertazzi $2004^{26}$ & 3 arm: $\mathrm{Ca}, \mathrm{OHC}, \mathrm{P}$ & 500 & $6 \mathrm{mo}$ & Community & 153 & $51 / 50$ & 100 & 68 \\
\hline Prince $2006^{61}$ & 2 arm: Ca, $P$ & 1200 & $5 y$ & Community & 1460 & $730 / 730$ & 100 & 75 \\
\hline Reid $2006^{62}$ & 2 arm: Ca, $P$ & 1000 & $5 y$ & Community & 1471 & $732 / 739$ & 100 & 74 \\
\hline Manios $2007^{28}$ & 3 arm: Ca, dairy, control & 600 & $12 \mathrm{mo}$ & Community & 112 & $26 / 36$ & 100 & 62 \\
\hline Reid $2008^{65}$ & 3 arm: Ca, Ca, P & 600 or 1200 & $2 y$ & Community & 323 & $216 / 107$ & 0 & 56 \\
\hline Chailurkit 201067,68 & 2 arm: Ca, $\mathrm{P}$ & 500 & $2 y$ & Community & 404 & $178 / 165$ & 100 & 66 \\
\hline Nakamura $2012^{70}$ & 3 arm: Ca, Ca, P & 250 or 500 & $2 y$ & Community & 450 & $281 / 137$ & 100 & 60 \\
\hline
\end{tabular}

$\mathrm{Ca}=$ calcium; HRT=hormone replacement therapy; $\mathrm{P}=$ placebo; ex=exercise; NaF=sodium fluoride; restrict=restriction; $\mathrm{OMC}=$ ossein-mineral complex; $250 \mathrm{HD}=25$-hydroxyvitamin $\mathrm{D} ; \mathrm{NS}=$ not stated

*Total number of randomised participants in all treatment arms.

tNumber of participants in relevant arms from trial in whom bone mineral density was reported. 
Table 3 | Design of randomised controlled trials and selected baseline characteristics of eligible trials of calcium supplements that also used vitamin D supplements

\begin{tabular}{|c|c|c|c|c|c|c|c|c|c|}
\hline Trial & Design & $\begin{array}{l}\text { Calcium } \\
\text { dose }(\mathrm{mg} / \mathrm{d})\end{array}$ & Vitamin D dose (IU/d) & Duration & $\begin{array}{l}\text { Care } \\
\text { setting }\end{array}$ & $\begin{array}{l}\text { No of } \\
\text { participants* }\end{array}$ & $\begin{array}{l}\text { No in } \mathrm{Ca} / \\
\text { control } \\
\text { groupt }\end{array}$ & $\begin{array}{l}\% \\
\text { women }\end{array}$ & $\begin{array}{l}\text { Mean } \\
\text { age }(y)\end{array}$ \\
\hline Smith $1981^{33}$ & $2 \times 2$ factorial: $\mathrm{CaD}, \mathrm{ex}, \mathrm{ex} / \mathrm{CaD}, \mathrm{P}$ & 750 & 400 & $3 y$ & Institution & 80 & $21 / 30$ & 100 & 82 \\
\hline Orwoll $1990^{38}$ & 2 arm: $\mathrm{CaD}, \mathrm{P}$ & 1000 & 1000 & $3 y$ & Community & 86 & $41 / 36$ & 0 & 58 \\
\hline Chapuy $1992^{41}$ & 2 arm: CaD, P & 1200 & 800 & $18 \mathrm{mo}$ & Institution & 3270 & $27 / 29$ & 100 & 84 \\
\hline Aloia $1994^{44}$ & 3 arm: CaD, HRT/CaD, P/D & 600 & 400 & $2.9 \mathrm{y}$ & Community & 118 & $34 / 36$ & 100 & 52 \\
\hline Chevalley $1994^{19}$ & 3 arm: CaD, OMC/D, P/D & 800 & $300000 \mathrm{IM}$ stat & $18 \mathrm{mo}$ & Community & 93 & $31 / 31$ & 89 & 72 \\
\hline Dawson-Hughes 199749 & 2 arm: CaD, $P$ & 500 & 700 & $3 y$ & Community & 445 & $187 / 202$ & 55 & 71 \\
\hline Baeksgaard $1998^{50}$ & 3 arm: CaD, CaD/multivitamins, $P$ & 1000 & 560 & $2 \mathrm{y}$ & Community & 160 & $65 / 63$ & 100 & 62 \\
\hline Chapuy $2002^{56}$ & 3 arm: CaD, CaD, P & 1200 & 800 & $2 \mathrm{y}$ & Institution & 610 & $393 / 190$ & 100 & 85 \\
\hline Grados $2003^{57}$ & 2 arm: CaD, $P$ & 500 & 400 & $12 \mathrm{mo}$ & Community & 192 & $95 / 97$ & 100 & 75 \\
\hline Doetsch $2004^{58}$ & 2 arm: CaD, $P$ & 1000 & 800 & $12 \mathrm{w}$ & Community & 30 & $16 / 14$ & NS & NS \\
\hline Harwood $2004^{14}$ & 4 arm: CaD, CaD, D, control & 1000 & $300000 \mathrm{IM}$ stat or 800 & $12 \mathrm{mo}$ & Community & 150 & $75 / 75$ & 100 & 81 \\
\hline Meier $2004^{59}$ & 2 arm: CaD, control & 500 & 500 & $6 \mathrm{mo}$ & Community & 55 & $27 / 16$ & 67 & 56 \\
\hline Riedt $2005^{60}$ & $\begin{array}{l}3 \text { arm: CaD/w-loss, D/w-loss, } \\
\text { w-maintain }\end{array}$ & 1200 & 400 & $6 \mathrm{mo}$ & Community & 55 & $23 / 24$ & 100 & 61 \\
\hline Jackson $2006^{7}$ & 2 arm: CaD, P & 1000 & 400 & $7 y$ & Community & 2431 & $1230 / 1201$ & 100 & 62 \\
\hline Bolton-Smith $2007^{63}$ & $\begin{array}{l}2 \times 2 \text { factorial: } \mathrm{CaD}, \mathrm{CaD} / \text { vit } \mathrm{K} \text {, vit } \\
\mathrm{K}, \mathrm{P}\end{array}$ & 1000 & 400 & $2 \mathrm{y}$ & Community & 244 & $99 / 110$ & 100 & 68 \\
\hline Bonnick $2007^{64}$ & 3 arm: CaD/alend, CaD, alend/D & 1000 & 400 & $2 \mathrm{y}$ & Community & 563 & $282 / 281$ & 100 & 66 \\
\hline Hitz $2007^{15}$ & 2 arm: CaD, P & 1200 & 1400 & $12 \mathrm{mo}$ & Community & 122 & $34 / 45$ & 83 & 68 \\
\hline Zhu $2008^{66}$ & 3 arm: $\mathrm{Ca}, \mathrm{CaD}, \mathrm{P}$ & 1200 & 1000 & $5 y$ & Community & 120 & $79 / 41$ & 100 & 75 \\
\hline Karkkainen $2010^{69}$ & 2 arm: CaD, control & 1000 & 800 & $3 y$ & Community & 593 & $287 / 306$ & 100 & 67 \\
\hline
\end{tabular}

$\mathrm{Ca}=$ calcium; HRT=hormone replacement therapy; $\mathrm{P}=$ placebo; $\mathrm{CaD}=\mathrm{co}$-administered calcium and vitamin $\mathrm{D}$; ex=exercise; OMC=0ssein-mineral complex; $\mathrm{D}=$ vitamin $\mathrm{D} ; \mathrm{IM}=$ intramuscular;

$\mathrm{w}$-loss=weight loss, $\mathrm{W}$-maintain=weight maintenance; vit $\mathrm{K}=$ vitamin $\mathrm{K}$; alend=alendronate; $\mathrm{NS}=$ not stated.

*Total number of randomised participants in all treatment arms.

tNumber of participants in relevant arms from trial in whom bone mineral density was reported.

Table 4 | Summary of selected characteristics of eligible trials of calcium intake. Data are number (percentage) of trials

\begin{tabular}{lll}
$\begin{array}{l}\text { Characteristics of randomised controlled trials } \\
\text { Agent studied: }\end{array}$ & $\begin{array}{l}\text { Dietary sources of } \\
\text { calcium }(\mathbf{n}=\mathbf{1 5})\end{array}$ & $\begin{array}{l}\text { Calcium supplements } \\
(\mathbf{n}=51)\end{array}$ \\
\hline Calcium monotherapy & $11(73)$ & $36(71)$ \\
\hline Calcium with vitamin D & $4(27)$ & $13(25)$ \\
\hline Multi-arm study with calcium or calcium+vitamin D & 0 & $2(4)$ \\
\hline Calcium dose $\geq 1000 \mathrm{mg} / \mathrm{d}$ & $6(40)$ & $34(67)$ \\
\hline Calcium dose $\leq 500 \mathrm{mg} / \mathrm{d}$ & $2(13)$ & $7(14)$ \\
\hline Duration $\leq 2$ years & $15(100)$ & $37(73)$ \\
\hline Duration $\geq 3$ years & 0 & $13(25)$ \\
\hline Participants living in community & $15(100)$ & $45(88)$ \\
\hline Most participants women & $13(87)$ & $48(94)$ \\
\hline Baseline mean age $\geq 70$ & $2(13)$ & $18(35)$ \\
\hline Baseline mean dietary calcium intake $<800 \mathrm{mg} / \mathrm{d}$ & $9 / 13(69)$ & $26 / 39(67)$ \\
\hline
\end{tabular}

and selected baseline characteristics for trials of calcium supplements, without and with additional vitamin D, respectively. Further details are in tables A-C in appendix 2. Of the 15 randomised controlled trials of dietary sources of calcium, 10 used milk or milk powder, two used dairy products, and three used hydroxyapatite preparations. Of the 51 trials of calcium supplements, 36 studied calcium monotherapy, 13 co-administered $\mathrm{CaD}$, and two were multi-arm studies of both. Table 4 summarises other features of the trials. Most of them studied calcium without vitamin D in women aged $<70$ living in the community; the mean baseline dietary calcium intake was $<800 \mathrm{mg} /$ day; and most trials lasted $\leq 2$ years. A calcium dose of $>500 \mathrm{mg} /$ day was used in most trials, but a higher proportion of trials of calcium supplements used a dose of $\geq 1000 \mathrm{mg} /$ day. Table $C$ in appendix 2 shows our assessment of risk of bias. Of the 15 trials of dietary sources of calcium, we assessed two as low risk of bias, six as moderate risk, and seven as high risk. Of the 51 trials of calcium supplements, we assessed 19 as low risk of bias, 12 as moderate risk, and 20 as high risk.

\section{Primary analyses}

Table 5 summarises the results of the meta-analyses. Increasing calcium intake from dietary sources increased BMD by $0.6-1.0 \%$ at the total hip and total body at one year and by $0.7-1.8 \%$ at these sites and the lumbar spine and femoral neck at two years (figs 1 and 2 . There was no effect on BMD at the forearm.

When we restricted the analyses to the 12 randomised controlled trials of milk or dairy products, by excluding three trials of hydroxyapatite, there was little change in the results. Calcium supplements increased BMD at all five skeletal sites by $0.7-1.4 \%$ at one year (figs 3 and 4 ), by $0.8-1.5 \%$ at two years (figs 5 and 6 ), and by $0.8-1.8 \%$ at more than two and a half years (fig 7) (range of duration of trials was three to five years).

When we used Egger's regression model and visual inspection of funnel plots, data seemed skewed toward positive results with increased calcium intake from dietary sources or supplements in about half of analyses that included five or more studies. The asymmetry of the funnel plot was caused by more small-moderate sized studies reporting larger effects 


\begin{tabular}{|c|c|c|c|c|c|c|c|c|c|}
\hline \multirow[b]{2}{*}{ Time point (years) } & \multicolumn{4}{|c|}{ Trials of dietary sources of calcium } & \multicolumn{4}{|c|}{ Calcium supplement trials } & \multirow[b]{2}{*}{$\mathrm{P}$ (interaction) $\dagger$} \\
\hline & Studies & Participants & $\begin{array}{l}\text { BMD difference* } \\
(95 \% \mathrm{Cl})\end{array}$ & $P$ value & Studies & Participants & $\begin{array}{l}\text { BMD difference* } \\
(95 \% \mathrm{CI})\end{array}$ & $P$ value & \\
\hline \multicolumn{10}{|l|}{ Lumbar spine } \\
\hline 1 & 11 & 1260 & $0.6(-0.1$ to 1.3$)$ & 0.08 & 27 & 3866 & $1.2(0.8$ to 1.7$)$ & $<0.001$ & 0.13 \\
\hline 2 & 8 & 816 & 0.7 (0.3 to 1.2$)$ & 0.001 & 21 & 6115 & $1.1(0.7$ to 1.6$)$ & $<0.001$ & 0.19 \\
\hline$>2.5$ & 0 & - & - & - & 8 & 3861 & $1.0(0.3$ to 1.6$)$ & 0.003 & - \\
\hline \multicolumn{10}{|l|}{ Femoral neck } \\
\hline 1 & 8 & 1035 & $0.3(-0.3$ to 0.9$)$ & 0.30 & 19 & 2651 & $1.2(0.7$ to 1.8$)$ & $<0.001$ & 0.02 \\
\hline 2 & 7 & 783 & 1.8 (1.1 to 2.6$)$ & $<0.001$ & 14 & 2415 & $1.0(0.5$ to 1.4$)$ & $<0.001$ & 0.05 \\
\hline$>2.5$ & 0 & - & - & - & 5 & 2257 & $1.5(0.2$ to 2.9$)$ & 0.025 & - \\
\hline \multicolumn{10}{|l|}{ Total hip } \\
\hline 1 & 6 & 900 & $0.6(0.3$ to 1.0$)$ & 0.001 & 7 & 1159 & 1.4 (0.6 to 2.3$)$ & 0.001 & 0.08 \\
\hline 2 & 5 & 689 & 1.5 (0.7 to 2.4$)$ & $<0.001$ & 7 & 4366 & 1.3 (0.8 to 1.8$)$ & $<0.001$ & 0.63 \\
\hline$>2.5$ & 0 & - & - & - & 6 & 3835 & 1.2 (0.5 to 1.9) & 0.001 & - \\
\hline \multicolumn{10}{|l|}{ Forearm } \\
\hline 1 & 4 & 418 & $0.0(-0.4$ to 0.5$)$ & 0.85 & 10 & 791 & $1.0(0.2$ to 1.8$)$ & 0.014 & 0.04 \\
\hline 2 & 2 & 171 & $0.1(-0.3$ to 0.4$)$ & 0.65 & 10 & 857 & $1.5(0.5$ to 2.6$)$ & 0.005 & 0.01 \\
\hline$>2.5$ & 0 & & & & 5 & 437 & $1.8(0.2$ to 3.4$)$ & 0.025 & \\
\hline \multicolumn{10}{|l|}{ Total Body } \\
\hline 1 & 3 & 433 & 1.0 (0.3 to 1.8) & 0.009 & 10 & 1255 & 0.7 (0.4 to 1.1) & $<0.001$ & 0.47 \\
\hline 2 & 2 & 358 & 0.9 (0.5 to 1.3) & $<0.001$ & 6 & 3901 & 0.8 (0.5 to 1.1$)$ & $<0.001$ & 0.67 \\
\hline$>2.5$ & 0 & - & - & - & 7 & 4164 & $0.8(0.5$ to 1.1$)$ & $<0.001$ & - \\
\hline
\end{tabular}

*Weighted mean difference between groups in percentage change in bone mineral density (BMD) from baseline.

tTest for interaction between subgroup of trials of dietary sources of calcium and subgroup of calcium supplement trials.

of calcium on BMD than expected, raising the possibility of publication bias. Seven multi-arm randomised controlled trials included a dietary source of calcium arm and a calcium supplement arm, ${ }^{17} 19-222628$ which allowed a direct comparison of the interventions. There were no significant differences between groups in BMD at any site in any individual trial, and there were also no significant differences between groups in BMD at any site or any time point in the pooled analyses (table D, appendix 2). We also tested for differences between the results of the trials of dietary sources of calcium and the trials of calcium supplements by comparing the two groups in subgroup analyses (table 4). There were no differences between the groups at any time point at the lumbar spine, total hip, or total body. At the femoral neck, there were greater increases in BMD at one year in the calcium supplement trials than in the dietary calcium trials, but at two years we found the opposite-that is, greater changes with dietary calcium than with calcium supplements. At the forearm, there were increases in BMD in the calcium supplement trials but no effect in the trials of dietary sources of calcium.

\section{Subgroup analyses}

We carried out additional subgroup analyses when there were 10 or more trials in an analysis and three or more trials in each subgroup. In the trials of dietary sources of calcium, these criteria allowed analyses to be carried out only on the one year results for the lumbar spine. For the calcium supplement trials, we carried out analyses on the one year and two year results for the lumbar spine, femoral neck, and forearm results, and the one year result for total body. Table $\mathrm{E}$ in appendix 2 shows that there were no consistent differences between subgroups based on calcium monotherapy versus CaD, age, risk of bias, calcium dose of $\geq 1000 \mathrm{mg} /$ day versus $<1000 \mathrm{mg} /$ day, calcium dose of $\leq 500 \mathrm{mg} /$ day versus $>500 \mathrm{mg} /$ day, vitamin $\mathrm{D}$ dose, baseline dietary calcium intake, or baseline 25-hydroxyvitamin D level. We did not find enough trials to carry out subgroup analyses based on sex and residence (community versus institution).

\section{Discussion}

\section{Principal findings}

Increasing calcium intake from dietary sources slightly increased bone mineral density (BMD) (by 0.6-1.8\%) over one to two years at all sites, except the forearm where there was no effect. Calcium supplements increased BMD to a similar degree at all sites and all time points (by 0.7-1.8\%). In the randomised controlled trials of calcium supplements, the increases in BMD were present by one year, but there were no further subsequent increases. Thus the increases from baseline at both two and over two and half years at each site were similar to the increases at one year. The increases in BMD with dietary sources of calcium were similar to the increases with calcium supplements, except at the forearm, in both direct comparisons of the two interventions in multi-arm studies and in indirect comparisons of the two interventions through subgroup analyses. The increases in BMD were similar in trials of calcium monotherapy and $\mathrm{CaD}$, consistent with a recent meta-analysis reporting that vitamin D monotherapy had no effect on BMD. ${ }^{71}$ There were no differences in changes in BMD in 


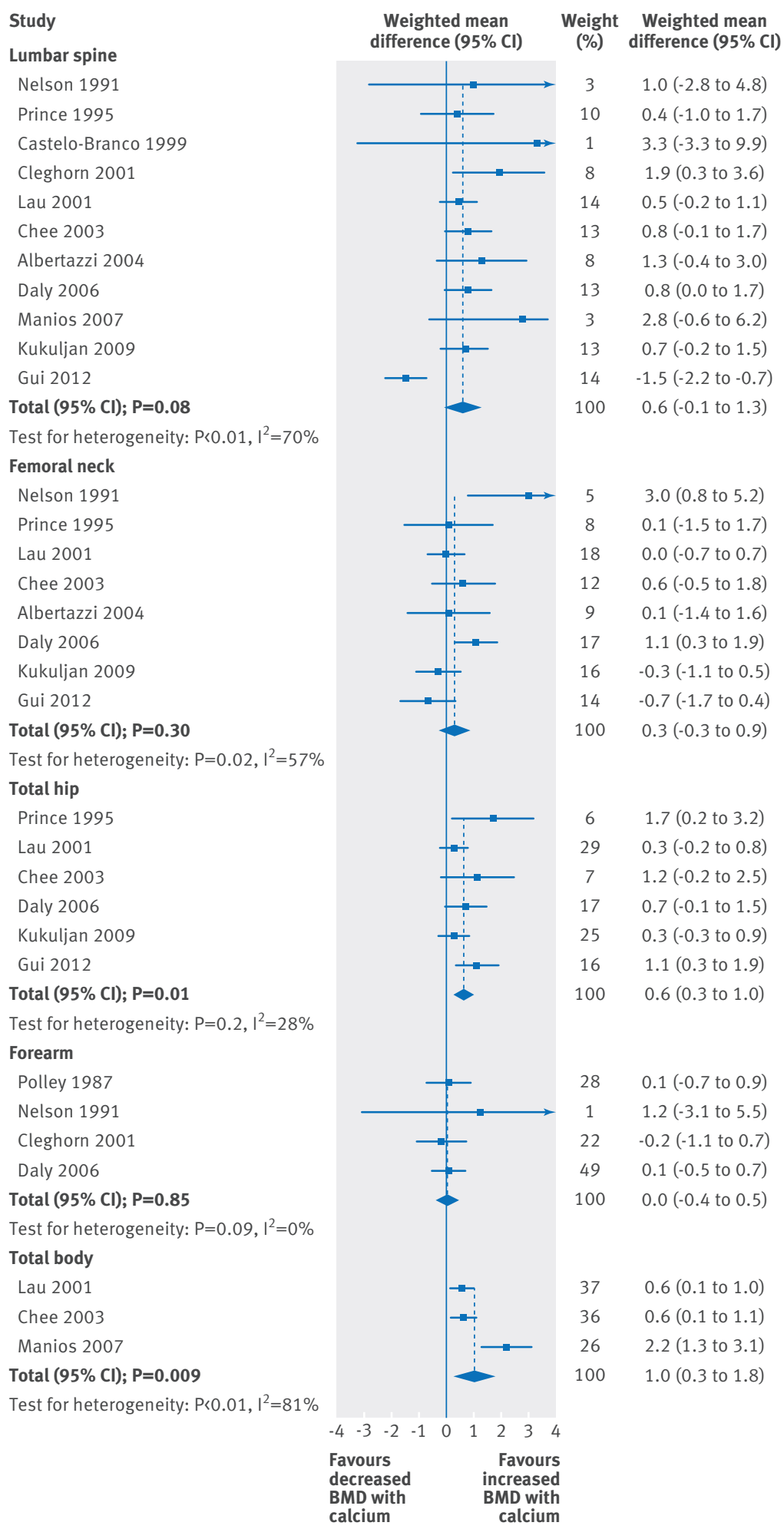

Fig 1 | Random effects meta-analysis of effect of dietary sources of calcium on percentage change in bone mineral density (BMD) from baseline at one year

our subgroup analyses between trials with calcium doses of $\geq 1000 \mathrm{mg} /$ day and $<1000 \mathrm{mg} /$ day or doses of $\leq 500 \mathrm{mg} /$ day and $>500 \mathrm{mg} /$ day, and in populations with baseline dietary calcium intake of $<800 \mathrm{mg} /$ day and $\geq 800 \mathrm{mg} /$ day. Overall, the results suggest that increasing calcium intake, whether from dietary sources or by taking calcium supplements, provides a small non-progressive increase in BMD, without any ongoing reduction in rates of BMD loss beyond one year. The similar effect of increased dietary intake and supplements suggests that the non-calcium components of the dietary sources of calcium do not directly affect BMD. 


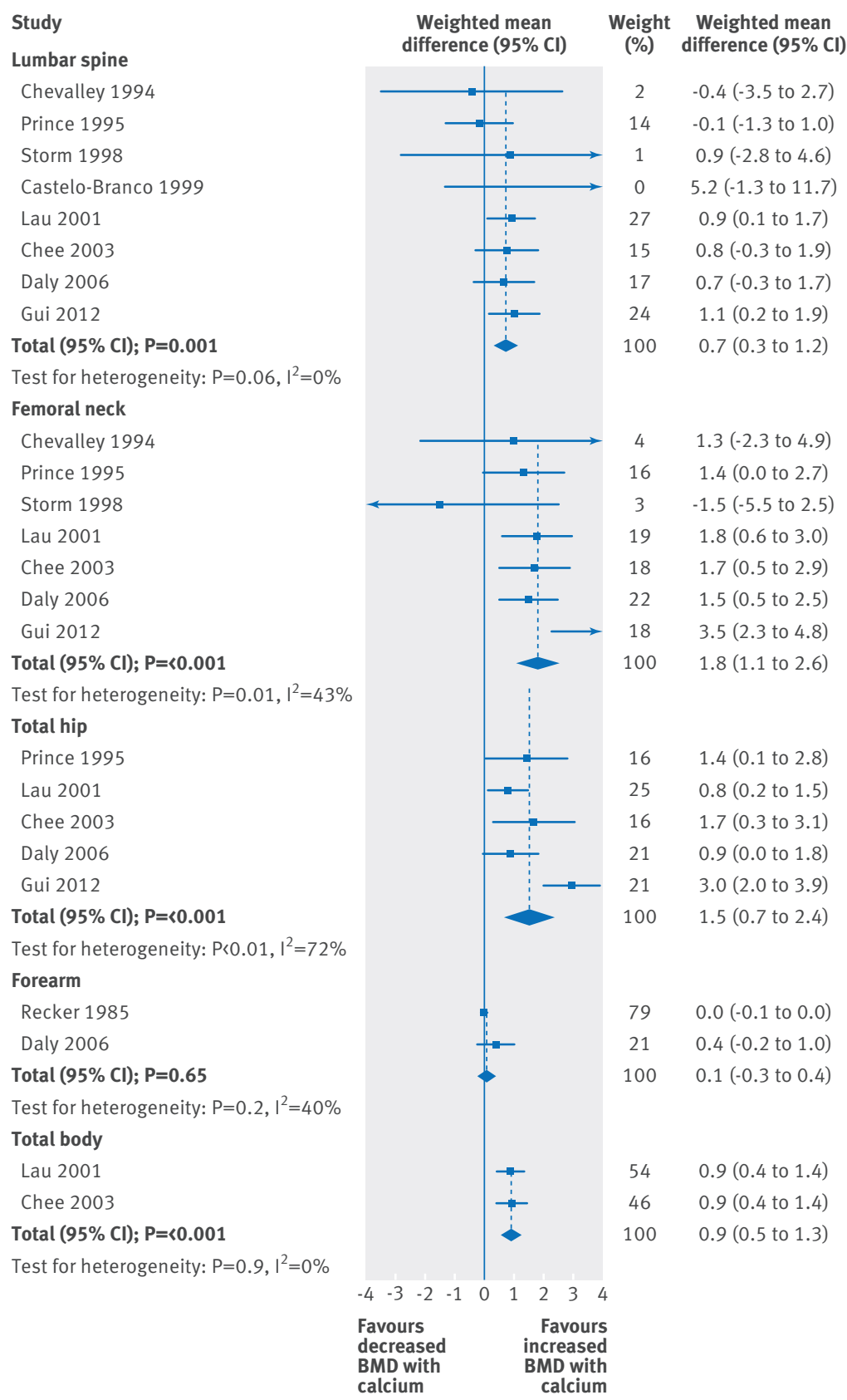

Fig 2 | Random effects meta-analysis of effect of dietary sources of calcium on percentage change in bone mineral density (BMD) from baseline at two years

\section{Strengths and limitations of the study}

The strength of this meta-analysis is its comprehensive nature. We included 59 randomised controlled trials and assessed the effects of both dietary calcium sources and calcium supplements on BMD at five skeletal sites and at three time points. The size of the review permitted a comparison of the effects on BMD of different sources of calcium-dietary sources or supplements-and also the effects in important subgroups such as those defined by dose of calcium, use of co-administered vitamin D, and baseline clinical characteristics. The results are consistent with those from an earlier meta-analysis of 15 randomised controlled trials of calcium supplements, which reported an increase in BMD of 1.6-2.0\% over two to four years. ${ }^{72}$

An important limitation is that BMD is only a surrogate for the clinical outcome of fracture. We undertook the review, however, because many of the subgroup analyses in the dataset of trials with fracture as an endpoint have limited power, ${ }^{10}$ and a comparison between randomised controlled trials of dietary sources of calcium and calcium supplements with fracture as the endpoint is not possible because only two small randomised controlled trials of dietary sources of calcium reported fracture data..$^{10}$ Another limitation is that in $60 \%$ of the meta-analyses, statistical heterogeneity between the studies was high $\left(I^{2}>50 \%\right)$. This indicates 


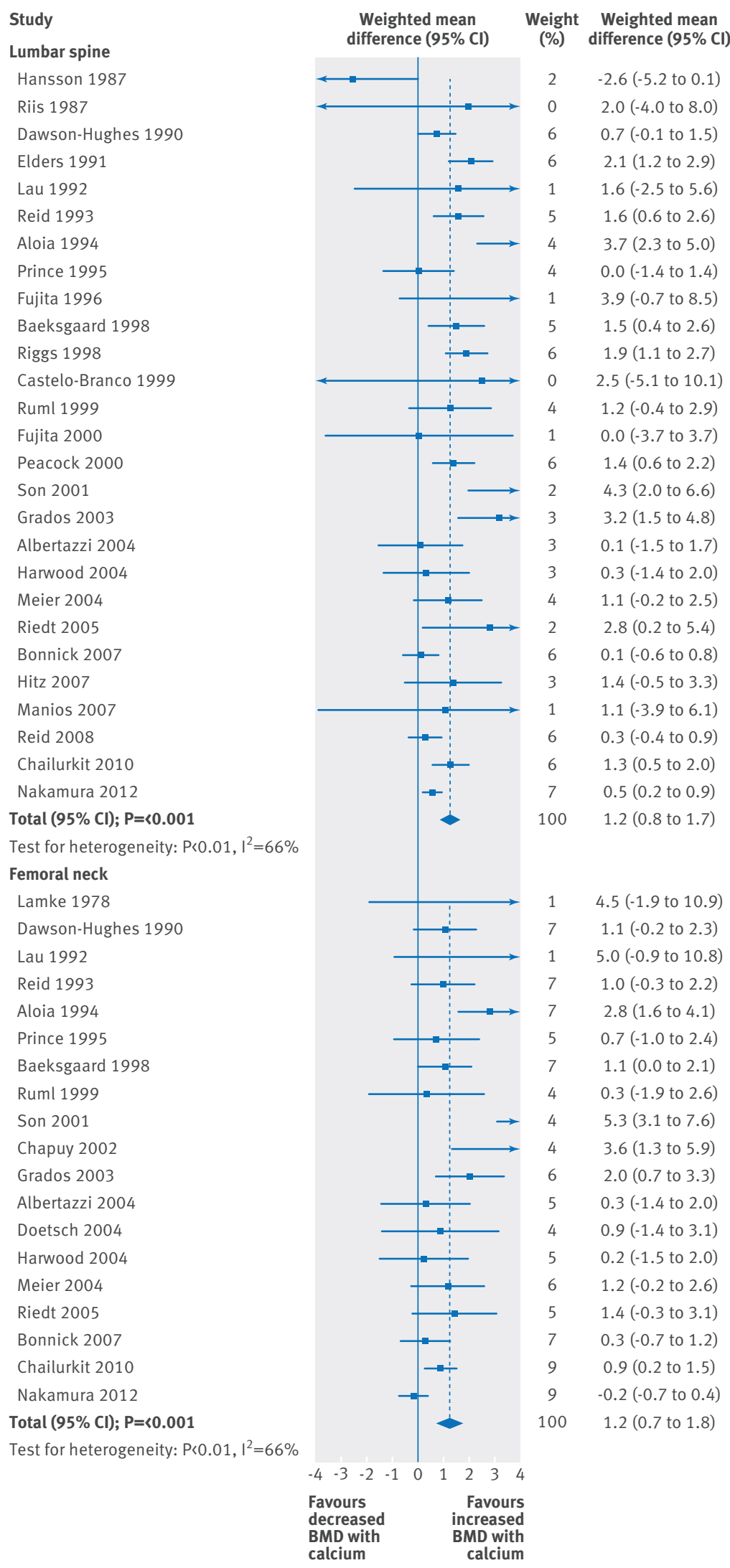

Fig 3 | Random effects meta-analysis of effect of calcium supplements on percentage change in bone mineral density (BMD) for lumbar spine and femoral neck from baseline at one year 


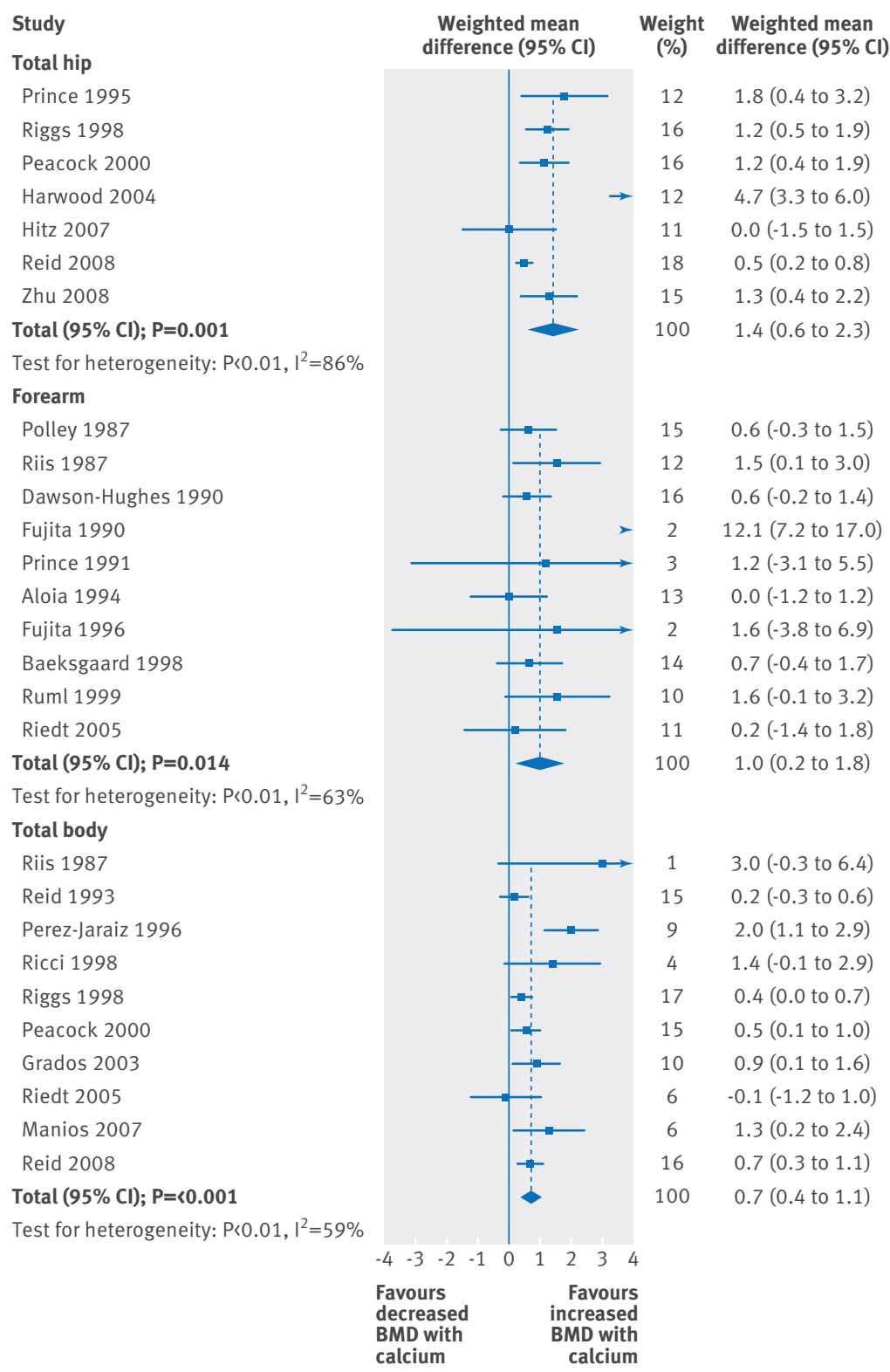

Fig 4 | Random effects meta-analysis of effect of calcium supplements on percentage change in bone mineral density (BMD) for total hip, forearm, and total body from baseline at one year

substantial variability in the results of included trials, although this was often because of the presence of a small number of outlying results. Subgroup analyses generally did not substantially reduce or explain the heterogeneity. We used random effects meta-analyses that take heterogeneity into account, and their results should be interpreted as reflecting the average result across the group of trials.

\section{Implications of findings}

The absence of any interaction with baseline dietary calcium intake or a dose-response relation suggests that increasing intake through dietary sources or through supplements does not correct a dietary deficiency (in which case greater effects would be seen in those with the lowest intakes or the highest doses). An alternative possibility is that increasing calcium intake has a weak anti-resorptive effect. Calcium supplements reduce markers of bone formation and resorption by about $20 \%, 626573$ and increasing milk intake also reduces bone turnover by a similar amount. ${ }^{74}$ Suppression of bone turnover by this amount might lead to the small observed increases in BMD.

Increases in BMD of about $1-2 \%$ over one to five years are unlikely to translate into clinically meaningful reductions in fractures. The average rate of BMD loss in older post-menopausal women is about $1 \%$ a year. So the effect of increasing calcium intake is to prevent about one to two years of normal BMD loss, and if calcium intake is increased for more than one year it will slow down but not stop BMD loss. Epidemiological studies suggest that a decrease in BMD of one standard deviation is associated with an increase in the relative risk of fracture of about $1 \cdot 5-2 \cdot 0 .{ }^{75} \mathrm{~A}$ one standard 


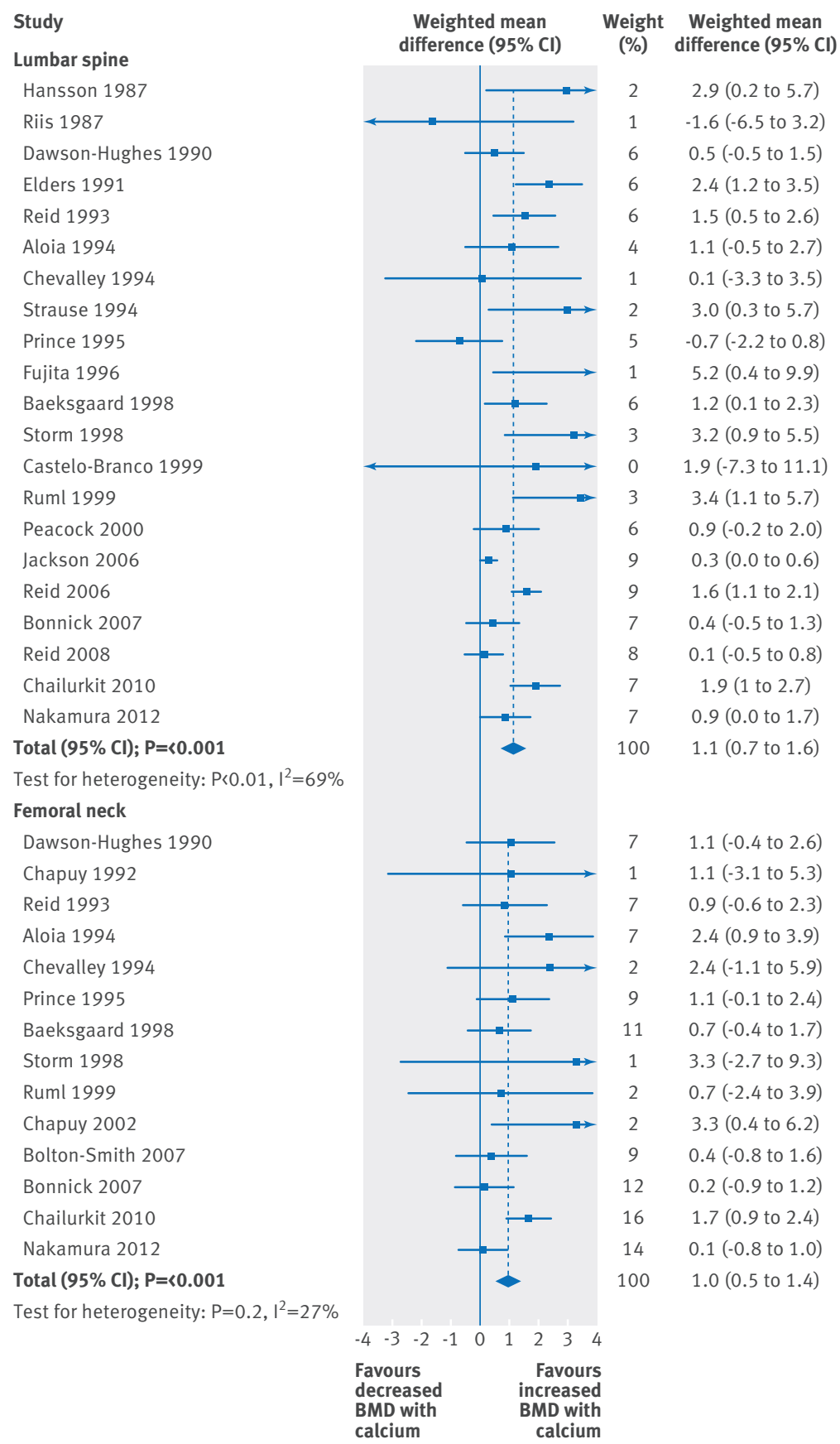

Fig 5 | Random effects meta-analysis of effect of calcium supplements on percentage change in bone mineral density (BMD) for lumbar spine and femoral neck from baseline at two years

deviation change in BMD is about equivalent to a $10 \%$ change in BMD. Based on these calculations, a $10 \%$ increase in BMD would be associated with a $33-50 \%$ reduction in risk of fracture. Therefore, the $1-2 \%$ increase in BMD observed with increased calcium intake would be predicted to produce a $5-10 \%$ reduction in risk of fracture. These estimates are consistent with findings from randomised controlled trials of other agents. The modest increases in BMD with increased calcium intake are smaller than observed with weak anti-resorptive agents such as etidronate ${ }^{76}$ and raloxifene. ${ }^{77}$ Etidronate, however, does not reduce vertebral or non-vertebral fractures, and raloxifene reduces vertebral but not non-vertebral fractures. ${ }^{78}$ In contrast, potent anti-resorptive agents such as alendronate, zoledronate, and denosumab increase BMD by 6-9\% at the spine and 5-6\% at the hip over three years. ${ }^{79-82}$ These changes are associated with reductions of $44-70 \%$ in vertebral fracture, $35-41 \%$ in hip fracture, and $15-25 \%$ in non-vertebral fractures. ${ }^{78}$ The magnitude of fracture reduction predicted by the small increases in BMD we observed with increased calcium intake are also consistent with the findings of our systematic review of calcium supplements and fracture. ${ }^{10}$ We observed small $(<15 \%)$ inconsistent reductions in total and vertebral fracture overall but no reductions in fractures in the 


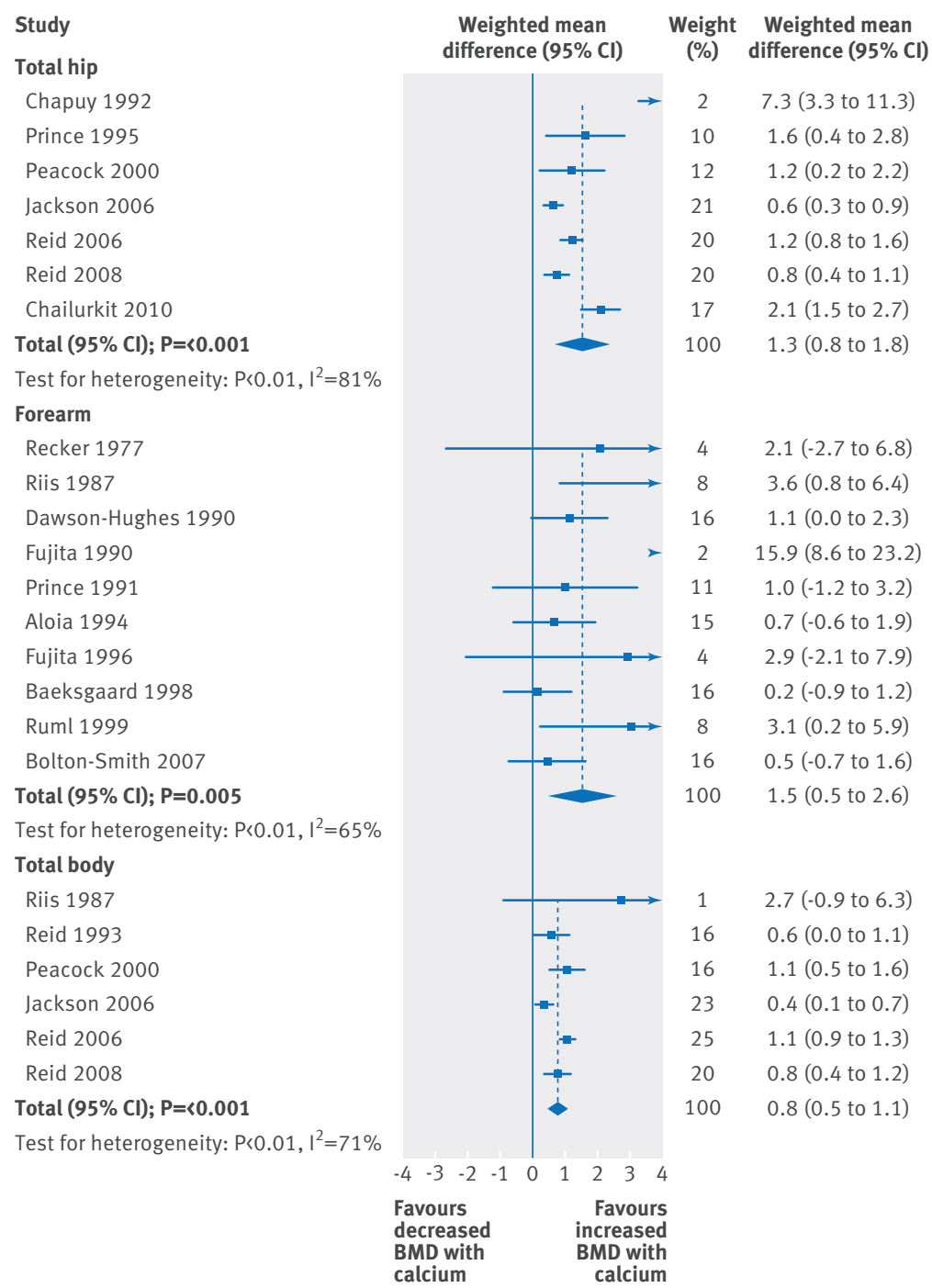

Fig 6 | Random effects meta-analysis of effect of calcium supplements on percentage change in bone mineral density (BMD) for total hip, forearm, and total body from baseline at two years

large randomised controlled trials at lowest risk of bias and no reductions in forearm or hip fractures.

The large number of randomised controlled trials that studied increased calcium intake and BMD and the consistency of the results across different populations in studies using higher or lower doses of calcium and in studies of dietary calcium sources or calcium supplements does not reveal any obvious gaps in the evidence. Any future trials conducted should have a strong rationale as to why the results are likely to differ from the large body of existing trial evidence. It is usually recommended that anti-resorptive agents are co-prescribed with calcium and vitamin $\mathrm{D}$, although randomised controlled trials of such agents have shown reductions in risk of fracture ${ }^{83-85}$ and the expected increases in BMD $^{6486-88}$ without the co-administration of calcium and vitamin D. Randomised controlled trials clarifying the role of calcium and vitamin D in individuals using anti-resorptive agents might be valuable. In subgroup analyses, we stratified trials by thresholds of baseline dietary calcium intake ( $800 \mathrm{mg} /$ day) and 25-hydroxyvi- tamin D (50 nmol/L). The clinical consequences of low calcium intake or vitamin D status such as osteomalacia, however, probably occur only at much lower thresholds, and there might also be interactions between calcium intake and vitamin $\mathrm{D}$ status. Analyses of individual patient data would be valuable in exploring these issues further.

\section{Conclusions}

In summary, increasing calcium intake from dietary sources increases BMD by a similar amount to increases in BMD from calcium supplements. In each case, the increases are small (1-2\%) and non-progressive, with little further effect on BMD after a year. Subgroup analyses do not suggest greater benefits of increasing calcium intake on BMD in any subpopulation based on clinically relevant baseline characteristics. The small effects on BMD are unlikely to translate into clinically meaningful reductions in fractures. Therefore, for most individuals concerned about their bone density, increasing calcium intake is unlikely to be beneficial. 


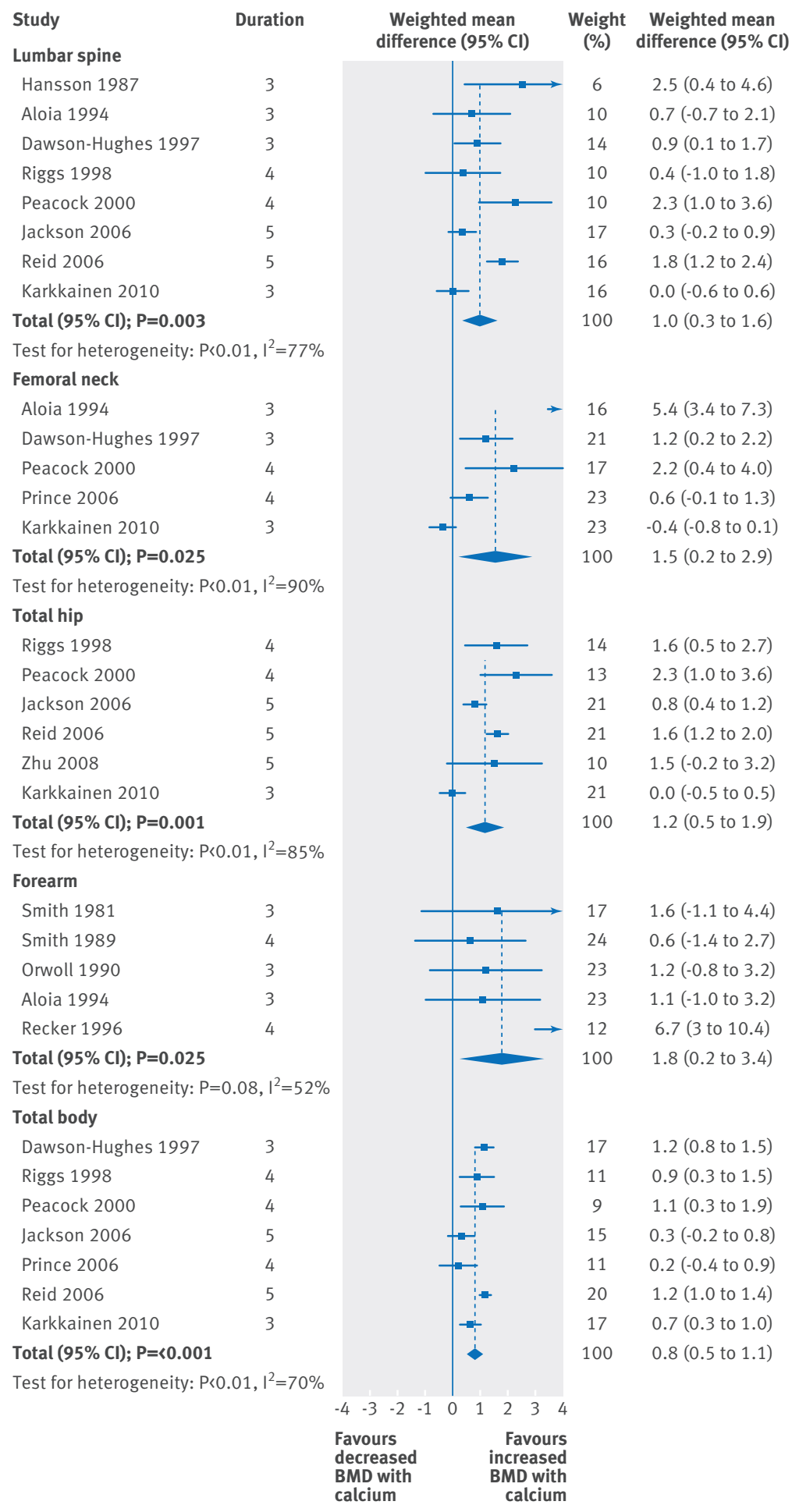

Fig 7 | Random effects meta-analysis of effect of calcium supplements on percentage change in bone mineral density (BMD) from baseline in studies that lasted more than two and a half years

Contributors: MJB, WL, VT, AG, and IRR designed the research. WL and MJB performed the literature searches. VT and MB extracted or checked data. MJB performed the analyses. MJB and VT drafted the paper. All authors critically reviewed and improved it. MJB is guarantor. All authors had access to all the data and take responsibility for the integrity of the data and the accuracy of the data analysis.

Funding: This study was funded by the Health Research Council (HRC) of New Zealand. The authors are independent of the HRC. The HRC had no role in study design, the collection, analysis, and interpretation of data, the writing of the article, or the decision to submit it for publication.
Competing interests: All authors have completed the ICMJE uniform disclosure form athttp://www.icmje.org/coi_disclosure.pdf and declare: MJB is the recipient of a Sir Charles Hercus health research fellowship; IRR has received research grants and honorariums from Merck, Amgen, Lilly, and Novartis.

Ethical approval: Not required

Transparency statement: MB affirms that the manuscript is an honest, accurate, and transparent account of the study being reported; that no important aspects of the study have been omitted; and that any discrepancies from the study as planned have been explained. 
Data sharing: No additional data available.

This is an Open Access article distributed in accordance with the Creative Commons Attribution Non Commercial (CC BY-NC 4.0) license, which permits others to distribute, remix, adapt, build upon this work non-commercially, and license their derivative works on different terms, provided the original work is properly cited and the use is noncommercial. See: http://creativecommons.org/licenses/by-nc/4.0/.

1 Consensus conference: Osteoporosis. JAMA 1984;252:799-802.

2 IOM (Institute of Medicine). Dietary reference intakes for calcium and vitamin D. National Academies Press, 2011.

3 Tang BMP, Eslick GD, Nowson C, Smith C, Bensoussan A. Use of calcium or calcium in combination with vitamin D supplementation to prevent fractures and bone loss in people aged 50 years and older: a meta-analysis. Lancet 2007;370:657-66.

4 Bolland MJ, Barber PA, Doughty RN, et al. Vascular events in healthy older women receiving calcium supplementation: randomised controlled trial. BMJ 2008;336:262-6.

5 Bolland MJ, Avenell A, Baron JA, et al. Effect of calcium supplements on risk of myocardial infarction and cardiovascular events: meta-analysis. BMJ 2010;341:c3691

6 Bolland MJ, Grey A, Avenell A, Gamble GD, Reid IR. Calcium supplements with or without vitamin D and risk of cardiovascular events: reanalysis of the Women's Health Initiative limited access dataset and meta-analysis. BMJ 2011;342:d2040.

7 Jackson RD, LaCroix AZ, Gass M, et al. Calcium plus vitamin D supplementation and the risk of fractures. NEngl/ Med 2006:354:669-83.

8 Lewis JR, Zhu K, Prince RL. Adverse events from calcium supplementation: relationship to errors in myocardial infarction self-reporting in randomized controlled trials of calcium supplementation. J Bone Miner Res 2012;27:719-22.

9 Bauer DC. Clinical practice. Calcium supplements and fracture prevention. N Engl/ Med 2013;369:1537-43.

10 Bolland MJ, Leung W, Tai V, et al. Calcium intake and risk of fracture: systematic review. BMJ 2015;351:h4580.

11 Higgins JPT, Green S, eds. Cochrane handbook for systematic reviews of interventions. Version 5.1.0 [updated March 2011]. Cochrane Collaboration, 2011. www.cochrane-handbook.org

12 Hansson T, Roos B. The effect of fluoride and calcium on spinal bone mineral content: a controlled, prospective (3 years) study. Calcif Tissue Int 1987;40:315-7.

13 Peacock M, Liu G, Carey M, et al. Effect of calcium or $250 \mathrm{H}$ vitamin D3 dietary supplementation on bone loss at the hip in men and women over the age of 60. / Clin Endocrinol Metab 2000;85:3011-9.

14 Harwood RH, Sahota O, Gaynor K, Masud T, Hosking DJ. A randomised, controlled comparison of different calcium and vitamin D supplementation regimens in elderly women after hip fracture: the Nottingham Neck of Femur (NONOF) Study. Age Ageing 2004;33:45-51

15 Hitz MF, Jensen JE, Eskildsen PC. Bone mineral density and bone markers in patients with a recent low-energy fracture: effect of $1 \mathrm{y}$ of treatment with calcium and vitamin D. Am J Clin Nutr 2007;86:251-9.

16 Recker RR, Heaney RP. The effect of milk supplements on calcium metabolism, bone metabolism and calcium balance. Am J Clin Nutr 1985; $41: 254-63$

17 Polley KJ, Nordin BE, Baghurst PA, Walker CJ, Chatterton BE. Effect of calcium supplementation on forearm bone mineral content in postmenopausal women: a prospective, sequential controlled trial. J Nutr 1987;117:1929-35

18 Nelson ME, Fisher EC, Dilmanian FA, Dallal GE, Evans WJ. A 1-y walking program and increased dietary calcium in postmenopausal women: effects on bone. Am J Clin Nutr 1991;53:1304-11.

19 Chevalley T, Rizzoli R, Nydegger V, et al. Effects of calcium supplements on femoral bone mineral density and vertebral fracture rate in vitamin-D-replete elderly patients. Osteoporos Int 1994:4:245-52

20 Prince R, Devine A, Dick I, et al. The effects of calcium supplementation (milk powder or tablets) and exercise on bone density in postmenopausal women. J Bone Miner Res 1995;10:1068-75

21 Storm D, Eslin R, Porter ES, et al. Calcium supplementation prevents seasonal bone loss and changes in biochemical markers of bone turnover in elderly New England women: a randomized placebocontrolled trial. J Clin Endocrinol Metab 1998;83:3817-25.

22 Castelo-Branco C, Pons F, Vicente JJ, Sanjuan A, Vanrell JA. Preventing postmenopausal bone loss with ossein-hydroxyapatite compounds. Results of a two-year, prospective trial. / Reprod Med 1999;44:601-5.

23 Cleghorn DB, O'Loughlin PD, Schroeder BJ, Nordin BE. An open, crossover trial of calcium-fortified milk in prevention of early postmenopausal bone loss. Med J Aust 2001;175:242-5.

24 Lau EM, Woo J, Lam V, Hong A. Milk supplementation of the diet of postmenopausal Chinese women on a low calcium intake retards bone loss. J Bone Miner Res 2001;16:1704-9.

25 Chee WS, Suriah AR, Chan SP, Zaitun Y, Chan YM. The effect of milk supplementation on bone mineral density in postmenopausa Chinese women in Malaysia. Osteoporos Int 2003;14:828-34.
26 Albertazzi P, Steel SA, Howarth EM, Purdie DW. Comparison of the effects of two different types of calcium supplementation on markers of bone metabolism in a postmenopausal osteopenic population with low calcium intake: a double-blind placebo-controlled trial. Climacteric 2004; 7:33-40.

27 Daly RM, Brown M, Bass S, Kukulian S, Nowson C. Calcium- and vitamin D3-fortified milk reduces bone loss at clinically relevant skeletal sites in older men: a 2-year randomized controlled trial. J Bone Miner Res 2006;21:397-405.

28 Manios Y, Moschonis G, Trovas G, Lyritis GP. Changes in biochemical indexes of bone metabolism and bone mineral density after a 12-mo dietary intervention program: the Postmenopausal Health Study. Am J Clin Nutr 2007;86:781-9.

29 Kukuljan S, Nowson CA, Bass SL, et al. Effects of a multi-component exercise program and calcium-vitamin-D3-fortified milk on bone mineral density in older men: a randomised controlled trial. Osteoporos Int 2009:20:1241-51.

30 Gui JC, Brasic JR, Liu XD, et al. Bone mineral density in postmenopausal Chinese women treated with calcium fortification in soymilk and cow's milk. Osteoporos Int 2012;23:1563-70.

31 Recker RR, Saville PD, Heaney RP. Effect of estrogens and calcium carbonate on bone loss in postmenopausal women. Ann Intern Med 1977;87:649-55

32 Lamke B, Sjoberg HE, Sylven M. Bone mineral content in women with Colles' fracture: effect of calcium supplementation. Acta Orthop Scand 1978;49:143-6.

33 Smith EL Jr, Reddan W, Smith PE. Physical activity and calcium modalities for bone mineral increase in aged women. Med Sci Sports Exerc 1981;13:60-4

34 Riis B, Thomsen K, Christiansen C. Does calcium supplementation prevent postmenopausal bone loss? A double-blind, controlled clinical study. N Engl J Med 1987;316:173-7.

35 Smith EL, Gilligan C, Smith PE, Sempos CT. Calcium supplementation and bone loss in middle-aged women. Am I Clin Nutr 1989:50:833-42.

36 Dawson-Hughes B, Dallal GE, Krall EA, Sadowski L, Sahyoun N, Tannenbaum S. A controlled trial of the effect of calcium supplementation on bone density in postmenopausal women. N Engl J Med 1990;323:878-83.

37 Fujita T, Fukase M, Miyamoto H, Matsumoto T, Ohue T. Increase of bone mineral density by calcium supplement with oyster shell electrolysate. Bone Miner 1990:11:85-91.

38 Orwoll ES, Oviatt SK, McClung MR, Deftos LJ, Sexton G. The rate of bone mineral loss in normal men and the effects of calcium and cholecalciferol supplementation. Ann Intern Med 1990;112:29-34.

39 Elders PJ, Netelenbos JC, Lips P, et al. Calcium supplementation reduces vertebral bone loss in perimenopausal women: a controlled trial in 248 women between 46 and 55 years of age. / Clin Endocrino Metab 1991.73.533-40.

40 Prince RL, Smith M, Dick IM, et al. Prevention of postmenopausal osteoporosis. A comparative study of exercise, calcium supplementation, and hormone-replacement therapy. N Engl J Med 1991;325:1189-95.

41 Chapuy MC, Arlot ME, Duboeuf F, et al. Vitamin D3 and calcium to prevent hip fractures in the elderly women. N Engl / Med 1992;327:1637-42.

42 Lau EM, Woo J, Leung PC, Swaminathan R, Leung D. The effects of calcium supplementation and exercise on bone density in elderly Chinese women. Osteoporos Int 1992;2:168-73.

43 Reid IR, Ames RW, Evans MC, Gamble GD, Sharpe SJ. Effect of calcium supplementation on bone loss in postmenopausal women. $\mathrm{N}$ Engl J Med 1993;328:460-4

44 Aloia JF, Vaswani A, Yeh JK, Ross PL, Flaster E, Dilmanian FA. Calcium supplementation with and without hormone replacement therapy to prevent postmenopausal bone loss. Ann Intern Med 1994;120:97-103.

45 Strause L, Saltman P, Smith KT, Bracker M, Andon MB. Spinal bone loss in postmenopausal women supplemented with calcium and trace minerals. J Nutr 1994;124:1060-4.

46 Fujita T, Ohue T, Fujii Y, Miyauchi A, Takagi Y. Heated oyster shell-seaweed calcium (AAA Ca) on osteoporosis. Calcif Tissue Int 1996;58:226-30

47 Perez-Jaraiz MD, Revilla M, Alvarez de los Heros JI, Villa LF, Rico H. Prophylaxis of osteoporosis with calcium, estrogens and/or eelcatonin: comparative longitudinal study of bone mass. Maturitas 1996;23:327-32.

48 Recker RR, Hinders S, Davies KM, et al. Correcting calcium nutritional deficiency prevents spine fractures in elderly women. J Bone Miner Res 1996;11:1961-6.

49 Dawson-Hughes B, Harris SS, Krall EA, Dallal GE. Effect of calcium and vitamin D supplementation on bone density in men and women 65 years of age or older. N Engl / Med 1997;337:670-6.

50 Baeksgaard L, Andersen KP, Hyldstrup L. Calcium and vitamin D supplementation increases spinal BMD in healthy, postmenopausal women. Osteoporos Int 1998:8:255-60.

51 Ricci TA, Chowdhury HA, Heymsfield SB, Stahl T, Pierson RN Jr, Shapses $\mathrm{SA}$. Calcium supplementation suppresses bone turnover during weight reduction in postmenopausal women. J Bone Miner Res 1998;13:1045-50. 
52 Riggs BL, O'Fallon WM, Muhs J, O'Connor MK, Kumar R, Melton LJ 3rd. Long-term effects of calcium supplementation on serum parathyroid hormone level, bone turnover, and bone loss in elderly women. J Bone Miner Res 1998;13:168-74.

53 Ruml LA, Sakhaee K, Peterson R, Adams-Huet B, Pak CY. The effect of calcium citrate on bone density in the early and mid-postmenopausal period: a randomized placebo-controlled study. Am J Ther 1999;6:303-11.

54 Fujita T, Fujii Y, Goto B, Miyauchi A, Takagi Y. Peripheral computed tomography (pQCT) detected short-term effect of AAACa (heated oyster shell with heated algal ingredient HAI): a double-blind comparison with $\mathrm{CaCO} 3$ and placebo. J Bone Miner Metab 2000;18:212-15.

55 Son SM, Chun YN. Effect of oral therapy with alphacalcidol or calcium in Korean elderly women with osteopenia and low dietary calcium. Nutr Res 2001;21:1347-55.

56 Chapuy MC, Pamphile R, Paris E, et al. Combined calcium and vitamin D3 supplementation in elderly women: confirmation of reversal of secondary hyperparathyroidism and hip fracture risk: the Decalyos II study. Osteoporos Int 2002;13:257-64.

57 Grados F, Brazier M, Kamel S, et al. Effects on bone mineral density of calcium and vitamin D supplementation in elderly women with vitamin D deficiency. Joint Bone Spine 2003;70:203-8.

58 Doetsch AM, Faber J, Lynnerup N, Watjen I, Bliddal H, DanneskioldSamsoe B. The effect of calcium and vitamin D3 supplementation on the healing of the proximal humerus fracture: a randomized placebo-controlled study. Calcif Tissue Int 2004;75:183-8.

59 Meier C, Woitge HW, Witte K, Lemmer B, Seibel MJ. Supplementation with oral vitamin D3 and calcium during winter prevents seasonal bone loss: a randomized controlled open-label prospective trial. I Bone Miner Res 2004:19:1221-30.

60 Riedt CS, Cifuentes M, Stahl T, Chowdhury HA, Schlussel Y, Shapses SA. Overweight postmenopausal women lose bone with moderate weight reduction and $1 \mathrm{~g} /$ day calcium intake. J Bone Miner Res 2005;20:455-63.

61 Prince RL, Devine A, Dhaliwal SS, Dick IM. Effects of calcium supplementation on clinical fracture and bone structure: results of a 5-year, double-blind, placebo-controlled trial in elderly women. Arch Intern Med 2006;166:869-75.

62 Reid IR, Mason B, Horne A, et al. Randomized controlled trial of calcium in healthy older women. Am J Med 2006;119:777-85.

63 Bolton-Smith C, McMurdo ME, Paterson CR, et al. Two-year randomized controlled trial of vitamin K1 (phylloquinone) and vitamin D3 plus calcium on the bone health of older women. J Bone Miner Res 2007;22:509-19.

64 Bonnick S, Broy S, Kaiser F, et al. Treatment with alendronate plus calcium, alendronate alone, or calcium alone for postmenopausal low bone mineral density. Curr Med Res Opin 2007;23:1341-9.

65 Reid IR, Ames R, Mason B, et al. Randomized controlled trial of calcium supplementation in healthy, nonosteoporotic, older men. Arch Intern Med 2008;168:2276-82.

66 Zhu K, Devine A, Dick IM, Wilson SG, Prince RL. Effects of calcium and vitamin D supplementation on hip bone mineral density and calcium-related analytes in elderly ambulatory Australian women a five-year randomized controlled trial. / Clin Endocrinol Metab 2008;93:743-9.

67 Chailurkit LO, Saetung S, Thakkinstian A, Ongphiphadhanakul B, Rajatanavin R. Discrepant influence of vitamin D status on parathyroid hormone and bone mass after two years of calcium supplementation. Clin Endocrinol (Oxf) 2010;73:167-72.

68 Rajatanavin R, Chailurkit L, Saetung S, Thakkinstian A, Nimitphong H. The efficacy of calcium supplementation alone in elderly Thai women over a 2-year period: a randomized controlled trial. Osteoporos Int 2013;24:2871-7.

69 Karkkainen MK, Tuppurainen M, Salovaara K, et al. Does daily vitamin D $800 \mathrm{IU}$ and calcium $1000 \mathrm{mg}$ supplementation decrease the risk of falling in ambulatory women aged 65-71 years? A 3-year randomized population-based trial (OSTPRE-FPS). Maturitas 2010;65:359-65.

70 Nakamura K, Saito T, Kobayashi R, et al. Effect of low-dose calcium supplements on bone loss in perimenopausal and postmenopausal Asian women: a randomized controlled trial. J Bone Miner Res 2012;27:2264-70
71 Reid IR, Bolland MJ, Grey A. Effects of vitamin D supplements on bone mineral density: a systematic review and meta-analysis. Lancet 2014;383:146-55.

72 Shea B, Wells G, Cranney A, et al. Meta-analyses of therapies for postmenopausal osteoporosis. VII. Meta-analysis of calcium supplementation for the prevention of postmenopausal osteoporosis. Endocr Rev 2002:23:552-9.

73 Bristow SM, Gamble GD, Stewart A, et al. Acute and 3-month effects of microcrystalline hydroxyapatite, calcium citrate and calcium carbonate on serum calcium and markers of bone turnover: a randomised controlled trial in postmenopausal women. Br J Nutr 2014;112:1611-20

74 Bonjour.JP, Brandolini-Bunlon M, Boirie Y, et al. Inhibition of bone turnover by milk intake in postmenopausal women. Br J Nutr 2008;100:866-74.

75 Kanis JA, Borgstrom F, De Laet C, et al. Assessment of fracture risk. Osteoporos Int 2005;16:581-9.

76 Cranney A, Guyatt G, Krolicki N, et al. A meta-analysis of etidronate fo the treatment of postmenopausal osteoporosis. Osteoporos Int 2001;12:140-51.

77 Cranney A, Tugwell P, Zytaruk N, et al. Meta-analyses of therapies for postmenopausal osteoporosis. IV. Meta-analysis of raloxifene for the prevention and treatment of postmenopausal osteoporosis. Endocr Rev 2002;23:524-8.

78 Freemantle N, Cooper C, Diez-Perez A, et al. Results of indirect and mixed treatment comparison of fracture efficacy for osteoporosis treatments: a meta-analysis. Osteoporos Int 2013;24:209-17.

79 Liberman UA, Weiss SR, Broll J, et al. Effect of oral alendronate on bone mineral density and the incidence of fractures in postmenopausal osteoporosis. The Alendronate Phase III Osteoporosis Treatment Study Group. N Engl I Med 1995;333: 1437-43.

80 Cummings SR, Black DM, Thompson DE, et al. Effect of alendronate on risk of fracture in women with low bone density but without vertebral fractures: results from the Fracture Intervention Trial. JAMA 1998;280:2077-82

81 Black DM, Delmas PD, Eastell R, et al. Once-yearly zoledronic acid for treatment of postmenopausal osteoporosis. N Engl / Med 2007;356:1809-22

82 Cummings SR, San Martin J, McClung MR, et al. Denosumab for prevention of fractures in postmenopausal women with osteoporosis. N Engl J Med 2009;361:756-65.

83 Rossouw JE, Anderson GL, Prentice RL, et al. Risks and benefits of estrogen plus progestin in healthy postmenopausal women: principal results from the Women's Health Initiative randomized controlled trial. JAMA 2002;288:321-33.

84 Anderson GL, Limacher M, Assaf AR, et al. Effects of conjugated equine estrogen in postmenopausal women with hysterectomy: the Women's Health Initiative randomized controlled trial. JAMA 2004;291:1701-12.

85 McCloskey EV Beneton M, Charlesworth D, et al Clodronate reduces the incidence of fractures in community-dwelling elderly women unselected for osteoporosis: results of a double-blind, placebocontrolled randomized study. / Bone Miner Res 2007:22:135-41.

86 Hosking D, Chilvers CE, Christiansen C, et al. Prevention of bone loss with alendronate in postmenopausal women under 60 years of age. Early Postmenopausal Intervention Cohort Study Group. N Engl J Med 1998;338:485-92.

87 Grey A, Bolland MJ, Wattie D, Horne A, Gamble G, Reid IR. The antiresorptive effects of a single dose of zoledronate persist for two years: a randomized, placebo-controlled trial in osteopenic postmenopausal women. J Clin Endocrinol Metab 2009;94:538-44.

88 Grey A, Bolland M, Wong S, Horne A, Gamble G, Reid IR. Low-dose zoledronate in osteopenic postmenopausal women: a randomized controlled trial. J Clin Endocrinol Metab 2012;97:286-92.

(C) BMJ Publishing Group Ltd 2015

Appendix 1: Literature searches

Appendix 2: Supplementary tables A-F and figure A 